\title{
Trichilemmal Carcinoma of the Scalp in a Young Female: A Case Report
}

\author{
Qiuyu Jia (D), Yunyan Yuan, Dandan Mao, Guangdong Wen, Xue Chen \\ Department of Dermatology, Peking University People’s Hospital, Beijing, People's Republic of China \\ Correspondence: Xue Chen, Tel +86 1088325472, Email I38II280849@I63.com
}

\begin{abstract}
Trichilemmal carcinoma (TC) is a rare malignant cutaneous adnexal neoplasm originating from the outer root sheath of hair follicles, which occurs commonly in sun-exposed areas of the elderly. Here, we introduce a case of a 24-year-old woman with TC on her scalp.
\end{abstract} Keywords: trichilemmal carcinoma, young woman, scalp

\section{Introduction}

Trichilemmal carcinoma (TC) is a rare malignant cutaneous adnexal neoplasm, which originates from the outer root sheath of hair follicles. ${ }^{1}$ It occurs commonly in sun-exposed areas of the elderly, such as face, scalp, neck, and upper extremities. $^{2}$ Its typical manifestations are asymptomatic exophytic or polypoid mass, sometimes with ulceration, telangiectasia, scales, or rolled borders. ${ }^{2,3}$ Therefore, TC may be mistaken for squamous cell carcinoma, basal cell carcinoma, nodular melanoma or keratoacanthoma. Surgical excision is the most common treatment, and Mohs micrographic surgery (MMS) has been shown to be an ideal option. ${ }^{4}$ Regular follow-up after excision is needed, though local recurrence and metastasis are rare. ${ }^{2}$

Herein, we report the case of a 24 -year-old woman with TC on her scalp with no history of other tumors or sunburns.

\section{Case Report}

A 24-year-old woman presented to our hospital with a persistent lesion on her scalp for 3 years without any pain, pruritus or bleeding. On examination, the lesion was a firm, exophytic papule on her scalp in size of $8 \times 9 \mathrm{~mm}$, and multiple telangiectatic vessels were seen on the surface [Figure 1]. The lesion was no tenderness. She had no history of other disease and she was not receiving medical treatment at that time. There was no hereditary disease in her family. In addition, she is Asian and she had no history of sunburn.

Surgical excision was performed, and the pathological examination revealed that the tumor was composed of lobules and infiltrative pattern of growth. Cells at the periphery were palisaded in some lobules. The tumor cells had clear cytoplasm, atypical nuclei and a high mitotic index, and tumor cells were found on the margin. Periodic acid-Schiff (PAS) staining revealed that glycogen-rich cytoplasm was PAS-positive. Immunohistochemistry studies resulted in positivity for CK, CK-14 and CK-17, but negativity for carcinoembryonic antigen (CEA) and vimentin. Many tumor cells expressed Ki-67, p53, and p63 in a diffuse pattern. [Figure 2] To determine the depth of invasion, the head magnetic resonance imaging (MRI) was performed and the MRI result showed local skin sag on the top of her head without invasion of the skull [Figure 3].

Then, a wider surgical excision was performed in another hospital with the excision of the periosteum and the pathological finding demonstrated malignant trichilemmal carcinoma with tumor-free margins. A 15-month follow-up showed no recurrence. 


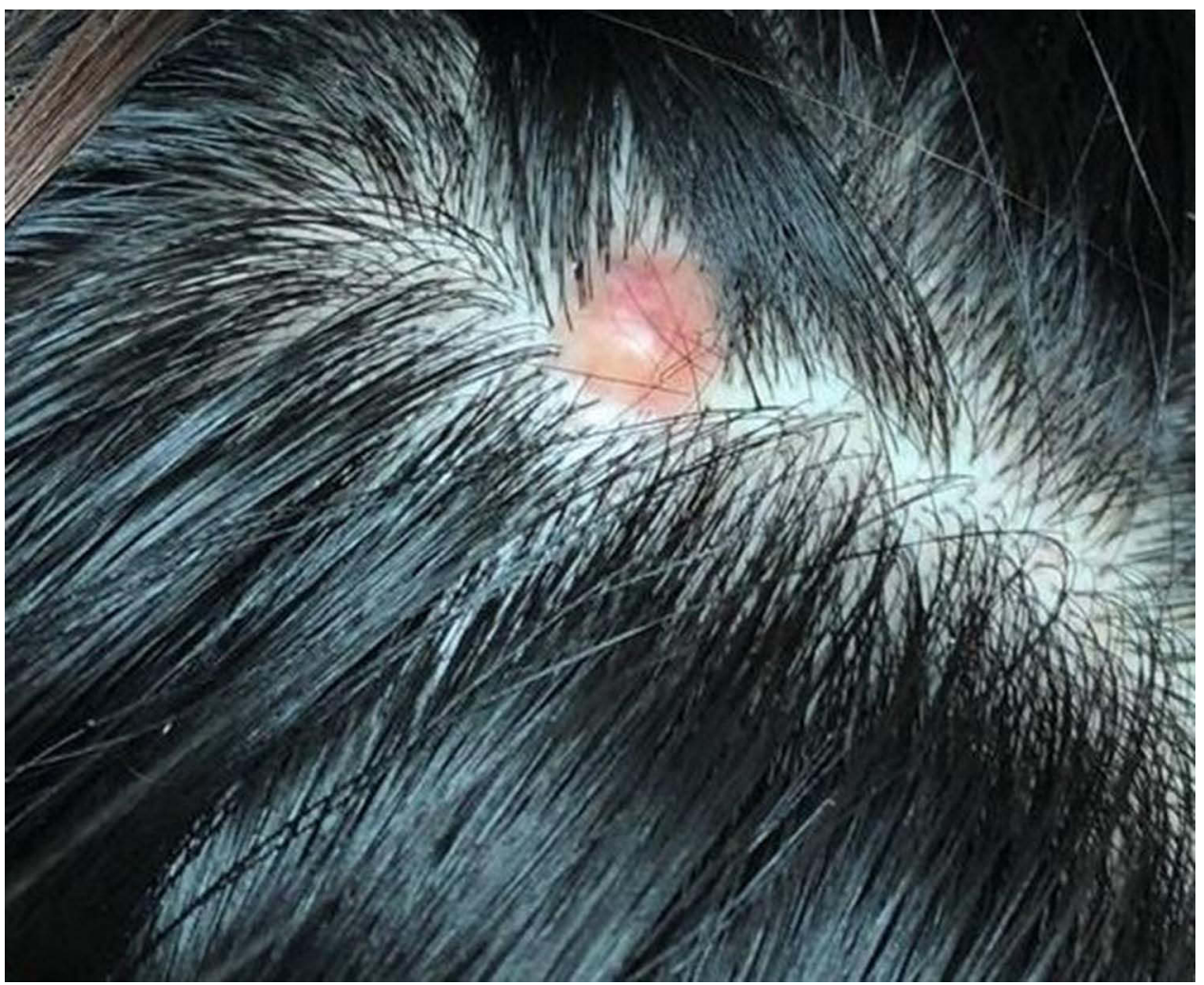

Figure I There was an exophytic papule on her scalp in size of $8 \times 9 \mathrm{~mm}$, and multiple telangiectatic vessels were seen on the surface.

\section{Discussion}

Trichilemmal carcinoma (TC) is a rare, cutaneous adnexal malignant neoplasm originating from the outer root sheath of hair follicles. TC usually occurs in sun-exposed areas of the body of the elderly, such as face, scalp, neck, and upper extremities. ${ }^{2}$ The pathogenesis of TC is not completely understood, but risk factors include ultraviolet and ionizing radiation, previous trauma or scar, genetic disorders (xeroderma pigmentosum and Cowden disease), and immunosuppression for solid organ transplantation., 5

Our patient was only 24 years old. It is very rare in TC, especially for healthy individuals, while the youngest case that has been reported up to now is a 9-year-old patient with xeroderma pigmentosa. ${ }^{1}$ The lesion of our patient occurred on her scalp on the top of head, which may be related to sun exposure, although she worked indoors all the time, and she had long hair. Based on a review of 103 TC cases, there were 11 cases whose lesions were found on the scalp. ${ }^{2}$

TC typically manifests as asymptomatic exophytic or polypoid mass measuring $0.5-7.5 \mathrm{~cm}$ that sometimes undergoes ulceration, telangiectasia, scales, or rolled borders. ${ }^{2,3}$ TC may be misdiagnosed as squamous cell carcinoma, basal cell carcinoma, nodular melanoma, or keratoacanthoma. Our case was misdiagnosed as basal cell carcinoma before the first excision.

Histologically, TC is composed of multiple intradermal lobules centering on a pilosebaceous unit. Malignant cells are characterized by prominent nucleoli, nuclear atypia and high mitotic rate, with large, clear glycogen-rich cytoplasm which is PAS-positive, diastase-sensitive and mucin negative. ${ }^{7,8}$ The cells at the periphery are often palisaded, and sometimes pagetoid spread can be seen. As for immunohistochemical staining, the presence of CK1, 10, 14 and 17 suggests the follicular infundibulum differentiation. TC is usually positive for p53, Ki67, c-erb-B2 and p63 but negative for epithelial membrane antigen and carcinoembryonic antigen. ${ }^{2,9,10}$ Therefore, the results of HE staining, PAS staining and immunohistochemical staining in our patient were in accordance with the characteristics of TC.

Complete surgical excision with tumor-free margins is the most common treatment. ${ }^{2}$ Mohs micrographic surgery (MMS) has been shown to be an ideal option because it provides a tissue-sparing method for complete surgical removal of the tumor while preserving the surrounding healthy tissue., ${ }^{4,11}$ Other therapeutic options that have been reported include $5 \%$ imiquimod, excision with frozen sections and adjuvant radiotherapy for patients with high-risk disease. ${ }^{2,7,8}$ 

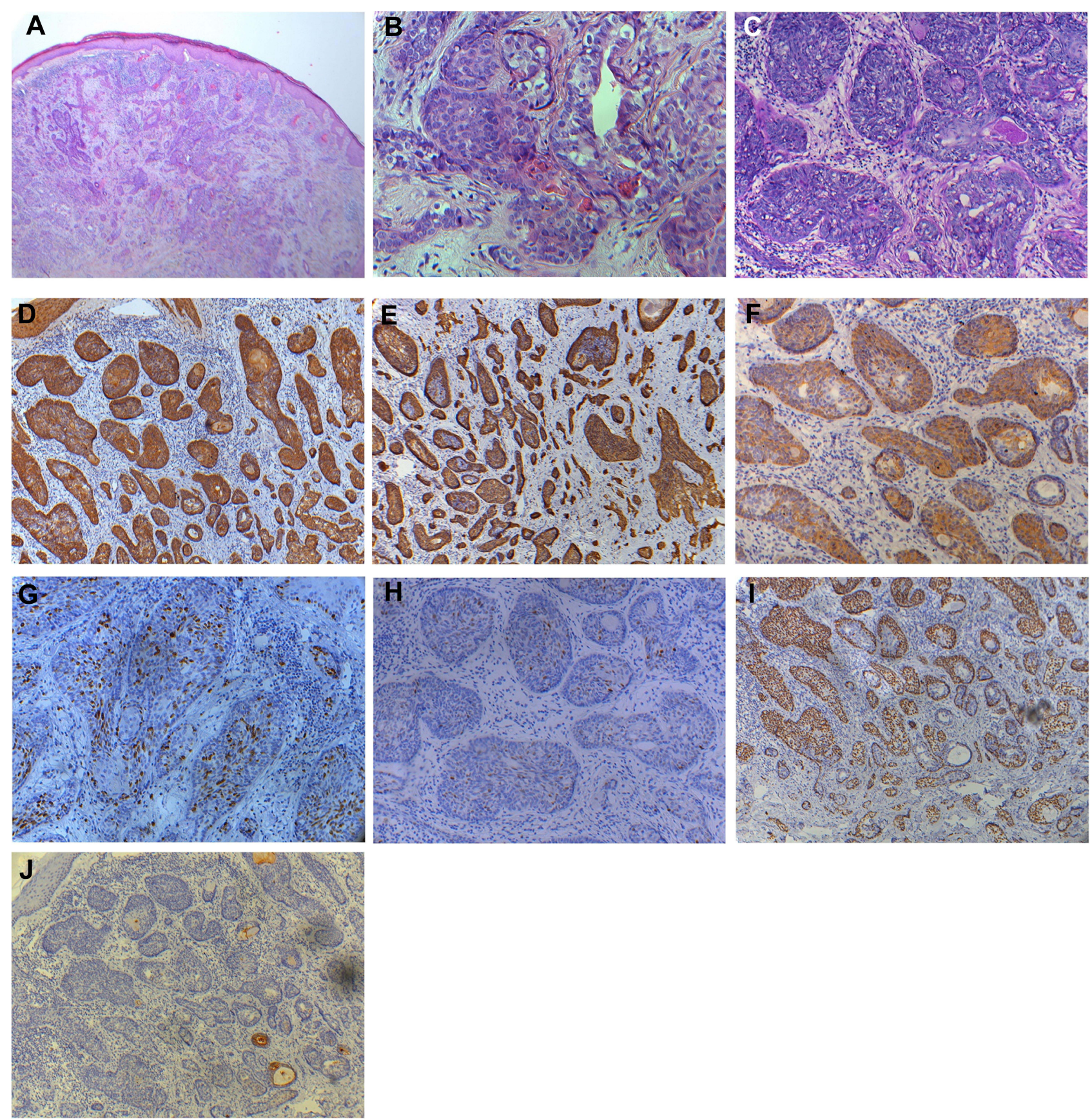

Figure 2 (A and B) Pathological examination revealed that the tumor was composed of lobules and infiltrative pattern of growth, and the tumor cells had clear cytoplasm, atypical nuclei and a high mitotic index in HE staining. (C) PAS staining revealed glycogen-rich cytoplasm was PAS-positive. (D-F) Immunohistochemistry studies resulted in positivity for CK, CK-I4 and CK-17. (G-I) Many tumor cells expressed Ki-67, p53, and p63 in a diffuse pattern. (J) Tumor cells were negative for CEA.

TC is locally aggressive but the clinical behavior tends to be relatively indolent. Local recurrence is rare but has been reported in several cases. ${ }^{2}$ Metastatic potential is very low in TC. Yi HS reported metastasis occurred at the aortocaval, paraaortic and portocaval regions after wide local excision of a TC in the left thigh. ${ }^{12} \mathrm{~K}$. Hiramatsu reported a case of TC with distant metastasis after renal transplantation. ${ }^{13}$ In addition, metastatic TC was also reported in a patient with breast cancer. ${ }^{14}$ Recently, Ha et al found TP53 mutations in TC patients who had an aggressive clinical course, so genetic alterations identified may further suggest the potential treatment options for TC. ${ }^{15}$ Regular follow-up for early detection of recurrence and metastasis is needed. Fifteen months after the second excision, no recurrence or metastasis was found in our case. However, our case was only 24 years old, longer follow-up should be performed. 


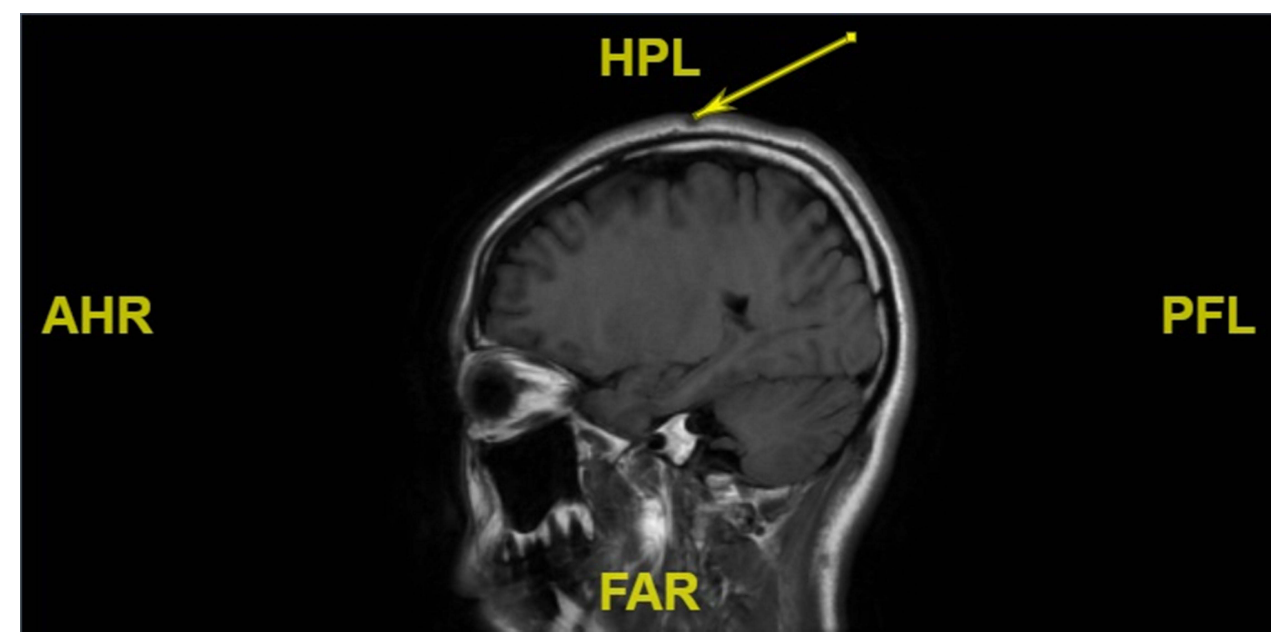

Figure $3 \mathrm{MRI}$ showed local skin sag on the top of her head without invasion of the skull.

\section{Ethics and Consent Statements}

Written informed consent was provided by the patient to have the case details and any accompanying images published. Institutional approval was not required to publish the case details.

\section{Disclosure}

The authors report no conflicts of interest in this work.

\section{References}

1. Reis JP, Tellechea O, Cunha MF, Baptista AP. Trichilemmal carcinoma: review of 8 cases. J Cutan Pathol. 1993;20:44-49. doi:10.1111/j.16000560.1993.tb01248.x

2. Hamman MS, Jiang SIB. Management of trichilemmal carcinoma: an update and comprehensive review of the literature. Dermatol Surg. 2014;40:711-717. doi:10.1111/dsu.0000000000000002

3. Wong TY, Suster S. Tricholemmal carcinoma. A clinicopathologic study of 13 cases. Am J Dermatopathol. 1994;16:463-473. doi:10.1097/ 00000372-199410000-00001

4. Tolkachjov SN, Hocker TL, Camilleri MJ, Baum CL. Mohs micrographic surgery in the treatment of trichilemmal carcinoma: the Mayo Clinic experience. J Am Acad Dermatol. 2015;72(1):195-196. doi:10.1016/j.jaad.2014.10.007

5. Kulahci Y, Oksuz S, Kucukodaci Z, Uygur F, Ulkur E. Multiple recurrence of trichilemmal carcinoma of the scalp in a young adult. Dermatol Surg. 2010;36(4):551-554. doi:10.1111/j.1524-4725.2010.01498.x

6. Mane DR, Kale AD, Hallikerimath S, et al. Trichilemmal carcinoma associated with xeroderma pigmentosa: report of a rare case. $J$ Oral Sci. 2010;52:505-507. doi:10.2334/josnusd.52.505

7. Jo J-H, Ko H-C, Jang H-S, et al. Infiltrative trichilemmal carcinoma treated with 5\% imiquimod cream. Dermatol Surg. 2005;31:973-976. doi:10.1097/00042728-200508000-00016

8. Lee JH, Shin YW, Oh YH, Lee YJ. Trichilemmal carcinoma of the upper eyelid: a case report. Korean J Ophthalmol. 2009;23:301-305. doi:10.3341/kjo.2009.23.4.301

9. Lee N, Oh S, Roh M. Trichilemmal carcinoma in a young adult. Indian J Dermatol Venereol Leprol. 2015;81:531-533. doi:10.4103/03786323.158644

10. Usseglio J, Pagès E, Guyot A, Laloze J, Ferri J. Trichilemmal carcinoma of the scalp. Int J Oral Maxillofac Surg. 2021;50(10):1289-1292. doi:10.1016/j.ijom.2021.02.008

11. Maya-Rico AM, Jaramillo-Pulgarín C, Londoño-García Á, et al. Locally aggressive trichilemmal carcinoma. An Bras Dermatol. 2018;93(4):579581. doi:10.1590/abd1806-4841.20187461

12. Yi HS, Sym SJ, Park J, et al. Recurrent and metastatic trichilemmal carcinoma of the skin over the thigh: a case report. Cancer Res Treat. 2010;42 (3):176-179. doi:10.4143/crt.2010.42.3.176

13. Hiramatsu K, Sasaki K, Matsuda M, et al. A case of trichilemmal carcinoma with distant metastases in a kidney transplantation patient. Transplant Proc. 2015;47:155-157. doi:10.1016/j.transproceed.2014.10.015

14. Sofianos C, Chauke NY, Grubnik A. Metastatic trichilemmal carcinoma in a patient with breast cancer. BMJ Case Rep. 2016;2016:undefined.

15. Ha JH, Lee C, Lee KS, et al. The molecular pathogenesis of Trichilemmal carcinoma. BMC Cancer. 2020;20(1):516. doi:10.1186/s12885-02007009-7 


\section{Publish your work in this journal}

Clinical, Cosmetic and Investigational Dermatology is an international, peer-reviewed, open access, online journal that focuses on the latest clinical and experimental research in all aspects of skin disease and cosmetic interventions. This journal is indexed on CAS. The manuscript management system is completely online and includes a very quick and fair peer-review system, which is all easy to use. Visit http://www. dovepress.com/testimonials.php to read real quotes from published authors.

Submit your manuscript here: https://www.dovepress.com/clinical-cosmetic-and-investigational-dermatology-journal 